\title{
Um jogo para estimular de forma divertida a consciência ambiental das crianças
}

\author{
Bruna Mariana F. de Souza ${ }^{2}$, Neila B. Xavier ${ }^{1}$, Emmerson S. R. Silva ${ }^{1}$, Miguel V. Oliveira ${ }^{3}$ \\ ${ }^{1}$ Departamento Acadêmico de Informação e Comunicação - Instituto Federal de Educação, \\ Ciência e Tecnologia do Amazonas (IFAM) - Manaus - AM - Brasil \\ 2Instituto de Computação - Universidade Federal do Amazonas (UFAM) - \\ Manaus - AM - Brasil \\ ${ }^{3}$ Núcleo de Computação - Universidade do Estado do Amazonas (UEA) - \\ Manaus - AM - Brasil \\ \{brunamfdsouza, neilaxavier, emmsr2004, migvanderlei\}@gmail.com
}

\begin{abstract}
This paper aims to present a way to increase awareness among children from 2nd to 5th grade about environmental pollution and its impacts, besides showing solutions that may be used to fight against some kinds of pollution. This can be achieved through U.M.E. a digital and interactive game that will help the child to understand the environmental problems arising from human attitudes, showing dialog boxes as a way of communication. The game has as main character a droid, who is responsible for alerting about the actions of environmental degradation and how to preserve it.
\end{abstract}

Resumo. $O$ objetivo deste artigo é apresentar uma forma divertida de conscientizar crianças do $2^{a}$ ao $5^{\circ}$ ano a respeito da poluição ambiental e dos impactos desta, além de mostrar algumas soluções que podem ser aplicadas para combater alguns tipos de poluição. Isto poderá ser alcançado por meio de U.M.E., um jogo digital e interativo, no qual ajudará a criança a compreender os problemas ambientais decorrentes das atitudes humanas, mostrando caixas de diálogo como modo de comunicação. O jogo tem como personagem principal um droide, que é responsável por alertar sobre as ações de degradação do meio ambiente e como preservá-lo.

\section{Introdução}

Segundo LAITMAN (2013), catástrofes ambientais estão cada vez mais frequentes nos últimos tempos. Segundo SKALEE et al. (2017) nos dias de hoje a conscientização ambiental se tornou imprescindível para que as pessoas tenham consciência de que a qualidade de vida desejada depende do seu cuidado com o meio em que vivemos.

Considerando que as crianças são o futuro da sociedade e público alvo desta pesquisa, espera-se prepará-las para terem um cuidado maior com o meio ambiente, diferente da população jovem e adulta dos dias atuais. Como diz MEDEIROS et al. 
(2010) é com a educação ambiental que o aluno pode dar início aos conhecimentos a respeito do meio ambiente.

$\mathrm{O}$ artigo tem como proposta apresentar uma forma divertida de conscientizar crianças do $2^{\circ}$ ao $5^{\circ}$ ano do ensino fundamental a respeito da poluição ambiental e dos impactos desta, além de mostrar algumas soluções que podem ser aplicadas para combater alguns tipos de poluição.

\section{Trabalhos Relacionados}

O trabalho de ANDRADE et al. (2012) apresenta o "Coletando", um jogo destinado a plataforma mobile em que quatro lixeiras de coleta seletiva são apresentadas: plástico, papel, metal e vidro. Espera-se que por meio dele o usuário aprenda como utilizar cada lixeira e a reciclar os materiais presentes em nosso dia a dia.

SKALEE et al. (2017), apresenta o desenvolvimento de uma aplicação digital chamada "Fredi no Mundo da Reciclagem", nela também são apresentadas cinco lixeiras: plástico, papel, vidro e material orgânico, onde o jogador deverá coletar os lixos e depositá-los na lixeira correta. No trabalho de SOUZA et al. (2011), o jogo intitulado de "UruBurbanos" busca aplicar atividades e práticas educativas, a respeito da limpeza urbana e educação ambiental, com o recolhimento dos lixos.

Em comparação aos trabalhos citados, o jogo Universal Machine Ecological (U.M.E.) aborda com mais ênfase a conscientização ambiental por explanar sobre mais de um tipo de poluição - que serão informados na seção 3 -, diferente dos demais jogos. É informado ao jogador alguns problemas decorrentes de práticas de degradação do meio ambiente no decorrer das fases, indo além do ensinamento da reciclagem e coleta seletiva, contudo, não deixa de versar sobre essas questões também.

\section{O Jogo}

Para a realização deste projeto foi adotada a pesquisa bibliográfica com abordagem qualitativa. O jogo terá como particularidade o compartilhamento facilitado do conhecimento e um diálogo acessível às crianças.

A aplicação será dividida em quatro fases, onde as crianças dispõem do auxílio de um personagem interativo na forma de um droide chamado U.M.E. Esse personagem tem como papel conscientizar as crianças sobre as poluições ambientais e ajudar a reduzir o impacto no meio ambiente, por meio de caixas de diálogos.

Este projeto utiliza o motor de jogo 3D Unity, mas a versão será desenvolvida em 2D. Com essa ferramenta de desenvolvimento, o jogo será disponibilizado em dois tipos de plataformas digitais: mobile e desktop.

A proposta é que as quatro fases estejam relacionadas a quatro diferentes tipos de poluição. As fases apresentam a poluição nas áreas: urbana, industrial, rural e florestal, incluindo áreas de desmatamento e queimadas. Cada fase conta com caixas de diálogo que são a parte principal do jogo, pois é por meio delas que o U.M.E. se comunicará com o jogador e então realizará a conscientização sobre a determinada poluição. Por essa razão 
o jogo não tem um tempo estimado de duração já que depende do tempo de leitura de cada jogador.

O objetivo do jogo, além de sensibilizar os jogadores a respeito da poluição que existe naquele ambiente, nas duas fases iniciais, é recolher os lixos antes que o contador termine a contagem, sendo este em um total de 20 segundos. Caso não tenha recolhido todo o lixo o jogador perde o jogo. Nas duas últimas fases, por serem tipos de poluição menos ligadas a lixos despejados, o objetivo se torna fazer com que o jogador compreenda as consequências que a poluição retratada tem sobre o meio ambiente e perceba a importância de uma mudança nesse contexto. A Seção 4 apresenta os resultados do projeto.

\section{Resultados e Discussão}

A Figura 1 apresenta a $1^{a}$ fase, na qual as crianças conhecerão mais sobre a poluição urbana. Por meio do painel mostrado também na figura, o U.M.E falará sobre os tipos de poluição que ocorrem na área urbana.

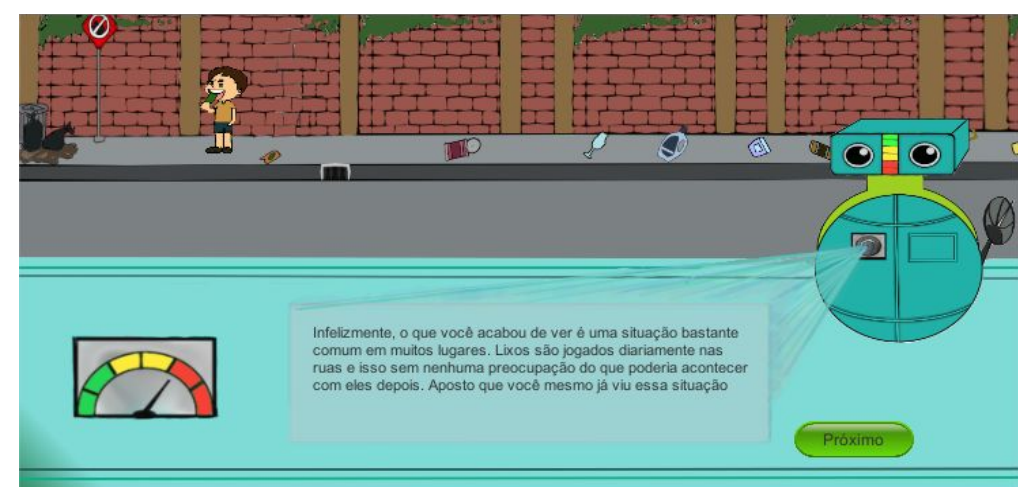

Figura 1 - Tela da Fase 1.

$\mathrm{Na}$ Figura 2, podemos observar a $2^{\mathrm{a}}$ fase, na qual será abordada a poluição industrial. O cenário tem uma indústria como plano de fundo, e posteriormente será exibido como era o mesmo local antes dela ser construída.

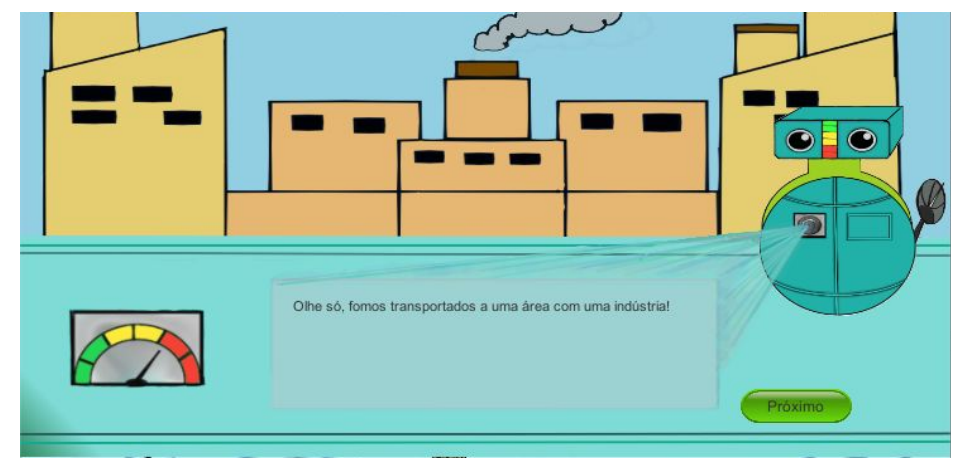

Figura 2 - Tela da Fase 2.

Foi realizado um teste com uma turma de 12 alunos (o percentual de aprovação dentre os alunos foi de 91,7\%) no laboratório da Escola Municipal João Valente. O jogo foi apresentado por meio de um datashow e as crianças foram divididas em grupos, onde 
cada grupo jogou uma fase enquanto os outros alunos assistiam pela projeção. Os resultados finais coletados por meio de um questionário respondido pela turma após a apresentação do jogo levam a concluir que os objetivos deste projeto foram alcançados, e que o jogo proposto tem condições de fazer o seu papel e conscientizar as crianças (e outros) sobre alguns dos problema ambientais. Ainda no teste verificamos que há indícios da necessidade desse jogo para fins de apoiar atividades relacionadas à conscientização ambiental, mas que ao mesmo tempo tenha uma proposta lúdica, interativa e linguagem facilitada para as crianças.

\section{Conclusão}

Muitos adultos não têm a consciência dos impactos que suas ações provocam no meio ambiente, consequentemente, para eles torna-se difícil contribuir com bons exemplos de conservação para as crianças. Isso torna necessário que estas fiquem sabendo desses assuntos por outros meios, como um jogo educativo, que é a proposta desse projeto.

O objetivo geral deste projeto é demonstrar por meio de um jogo alguns problemas ambientais e seus impactos no nosso planeta. Além disso, fazer com que os jogadores fiquem sensibilizados com as poluições retratadas para que assim ponham em prática o que aprenderam. E ainda se sintam instigados a pesquisar mais sobre elas e a mudarem seus hábitos e contribuírem para a diminuição dos impactos ambientais. Visando trabalhos futuros, espera-se aplicar ao jogo U.M.E. a funcionalidade de voz, para que o droide consiga se comunicar com as crianças que ainda não aprenderam a ler.

\section{Referências}

ANDRADE, M., Almeida, E., Silva, C., Melo, T. M., Oliveira, T., Falcão, F., Araújo, A. Coletando: Desenvolvimento de um jogo para o ensino-aprendizagem no campo da Educação Ambiental, 2012. Disponível em: <http://sbgames.org/ sbgames2012/proceedings/papers/cultura/C_S16.pdf\&ved=2ahUKEwjItbba2a_ZAh UBlpAKHZuoBCEQFjAAegQIDxAB\&usg=AOvVaw1sVC1Bq1RSa0s_5v4RtD89.

Acesso em: fevereiro/2018.

DE MEDEIROS, Aurélia Barbosa, LEMES, Maria José da Silva Mendonça, DE SOUSA, Gláucia Lourenço, DE OLIVEIRA, Itamar Pereira. A Importância da educação ambiental na escola nas séries iniciais, 2010.

LAITMAN, Michael. Conectados pela Lei da Natureza, ARI Publishers, 2013.

SKALEE, A. A., Kliszcz, S., Parreira, F. J., Silveira S. R. "Fredi no mundo da Reciclagem": Jogo Educacional Digital para Conscientização da Importância da Reciclagem, 2017. Disponível em: <http://seer.ufrgs.br/index.php/renote/article/ view/75103>. Acesso em: fevereiro/2018.

SOUZA, I.; AZEVEDO, R. R; SILVA, A. R. A.; NEGREIROS, G.; FREITAS, F.; FARIS, I. H.. UruBurbanos: um Jogo para Apoiar o Ensino-Aprendizagem de Educação Ambiental, 2011. Disponível em: <http://www.sbgames.org/ sbgames2011/proceedings/sbgames/papers/cult/full/91367_1.pdf $>$. Acesso em: março/2018. 